\title{
Computation of Energy Absorption and Residual Voltage in a Fourth Rail LRT Station Arresters in EMTP-RV: A Comparative Study
}

\author{
Farah Asyikin Abd Rahman ${ }^{1,2}$ (1) Mohd Zainal Abidin Ab Kadir ${ }^{1,3}$. \\ Ungku Anisa Ungku Amirulddin ${ }^{1} \cdot$ Miszaina Osman ${ }^{1}$
}

Received: 10 January 2021/Revised: 14 February 2021/ Accepted: 25 February 2021/Published online: 1 April 2021

(C) The Author(s) 2021

\begin{abstract}
This paper presents a study on the performance of a fourth rail direct current (DC) urban transit affected by an indirect lightning strike. The indirect lightning strike was replicated and represented by a lightning-induced overvoltage by means of the Rusck model, with the sum of two Heidler functions as its lightning channel base current input, on a perfect conducting ground. This study aims to determine whether an indirect lightning strike has any influence with regard to the performance of the LRT Kelana Jaya line, a fourth rail DC urban transit station arrester. The simulations were carried out using the Electromagnetic Transients Program-Restructured Version (EMTP-RV), which includes the comparison performance results between the 3EB4-010 arrester and PDTA09 arrester when induced by a $90 \mathrm{kA}(9 / 200 \mu \mathrm{s})$. The results demonstrated that the PDTA09 arrester showed better coordination with the insulated rail bracket of the fourth rail. It allowed a lower residual voltage and a more dynamic response, eventually resulting in better voltage gradient in the pre-breakdown region and decreased residual voltage ratio in the high current region.
\end{abstract}

Farah Asyikin Abd Rahman

niki_sya@yahoo.com

1 Institute of Power Engineering (IPE), Universiti Tenaga Nasional (UNITEN), 43200 Kajang, Selangor, Malaysia

2 Electrical Engineering Department, Politeknik Kota Kinabalu (PKK), 88460 Kota Kinabalu, Sabah, Malaysia

3 Centre for Electromagnetic and Lightning Protection Research (CELP), Advanced Lightning, Power and Energy Research (ALPER), Universiti Putra Malaysia (UPM), Serdang, Selangor, Malaysia

Communicated by Xiaofeng Yang.
Keywords DC transit - Electromagnetic Transients Program-Restructured Version · Fourth rail - Indirect lightning $\cdot$ Lightning-induced overvoltage $\cdot$ Surge arrester

\section{Introduction}

An insulation coordination study is defined as a selection of dielectric insulation strengths of equipment in avoiding any damage caused by overvoltage related to transient, in particular switching actions, lightning strikes, or phenomena related to fundamental-frequency overvoltage such as earth faults [1,2]. This study was introduced so as to arrange the dielectric insulation of different equipment in a raised level manner, as if one insulator fails to bring the transient overvoltage to a stop, then the next insulator should be able to do so. These insulations are also arranged so that the equipment at fault should bring the least damage and disturbance to the system, and will also be easy to repair and replace. The probability of failure of insulation is high at the weakest insulation point nearest the source of transient overvoltage. There are a few common insulation coordination studies as tabulated in Table 1 [2].

Interestingly, the insulation study concerning any urban transit system is not listed as a common insulation study in spite of the fact that this system originated around the same era as wind and solar power technologies, 1887 and 1839, respectively [3,4]. The transit system should be placed as highly important for mobility in societies that are becoming ever more urbanised. It is more than necessary to conduct an insulation coordination study as a precaution taken for system reliability assurance. Such a study may not necessarily be an insulation coordination study concerning overvoltage transients, as more than half of the metro stops in Latin America, the Middle East and North Africa 
Table 1 Common insulation studies and their description [2]

\begin{tabular}{ll}
\hline Insulation Study & Description \\
\hline $\begin{array}{l}\text { High-voltage } \\
\text { substation }\end{array}$ & $\begin{array}{c}\text { The study includes the determination of the probability of post insulator flashovers as well as the determination of } \\
\text { transformer insulation bearing an acceptable margin of protection. The study includes both the switching and } \\
\text { lightning surge analysis }\end{array}$ \\
$\begin{array}{l}\text { The study includes the determination of proper arrester locations and ratings applied on the lines that do not have pre- } \\
\text { insertion resistors installed on their breakers. Another common study is to determine installation location of arresters } \\
\text { to reduce the back-flashover rate of a line } \\
\text { The study includes the analysis of generator terminal insulation to the outgoing transmission or distribution lines. The } \\
\text { study considers both the incoming and internal surge sources }\end{array}$ \\
$\begin{array}{l}\text { The study includes a comparison between the expected transients on the power system and the insulation withstand of } \\
\text { the system. The study considers both the transients from arc furnaces and switching power supplies }\end{array}$ \\
$\begin{array}{l}\text { The related study is treated in a similar fashion to small power plants but has to consider the grounding and internal } \\
\text { switching surges }\end{array}$ \\
farms
\end{tabular}

(MENA), 70\% from Asian stops, $80 \%$ of Eurasian metros, and $75 \%$ of European metro systems are underground [5]. Other operating situations such as triggered fuses or operational switching can also generate surges and cause damage which is more than enough to drive an insulation coordination study. Furthermore, in the opinion of most researchers, as an overhead line running transit usually runs in an open area, it is thus highly susceptible to lightning, hence the overwhelming lightning protection studies and research development dedicated to this type of transit [6]. This is in contrast to the third rail transit studies, which are normally underground and therefore protected from lightning and seem highly attentive to the stray current matter in question, not including the efforts of refining the transit negative return circuit $[7,8]$.

Nonetheless, this creates a gap within the insulation studies, more so when Malaysian LRT Kelana Jaya line is among the three established fourth rail systems that run in a country that has the third highest lightning occurrences in the world [9]. Thus, this study served to fill the existing research gap regarding the lightning insulation coordination of an urban transit in particular the fourth rail traction.

\section{Overvoltage Transient Insulation Coordination Study on Urban Rail Transit System}

The good old days of electro-mechanical signalling, communication and control of the outmoded electric transit networks are long forgotten as they are being modernised in stages at different times by up-to-date ultrasensitive electronic circuits. These modernisation stages in turn have made the networks vulnerable to lightning transients, as these networks initially were not designed to reduce the lightning surges to the low levels tolerable to the newly added electronic circuits. On top of this is the emergence of contemporary transit railway arrangements which are already incorporated with advanced signalling, communication and control. Apart from being new and high-tech in railway arrangements, the contemporary transit railways also suffer erratically from the effects of lightning transients, because many of the established standards and guidelines that were referred to during the phase design of the networks date back to the age of electro-mechanical devices and hence do not subsume any robust transient protection design. Table 2 summarises the common incidents of lightning transients on an urban rail transit system [10].

A disruption in transit operation and apparatus arises due to lightning surge voltages and electromagnetic interference that surely creates traffic havoc, and it is necessary to provide an appropriate lightning protection set-up. Such set-ups always result in the improvement and revision of existing surge arresters, earthing electrodes or earth mesh worthy for LRT traction power supply equipment and substations, and telecommunication and signalling systems [11-19]. At the end of the day, all these discussed insulation coordination studies primarily focus on the overhead wire system that most metro transits in the world employ. The reasoning behind these studies is that most of the transit systems that run in an open area are composed of an overhead wire system, thus attracting any lightning discharge. This is unlike the third rail system that runs mostly on underground lines and is hence protected from lightning. However, if any of the line runs on the surface or is elevated, that particular section may be shielded by neighbouring buildings [16].

On the other hand, this study focuses on an elevated fourth rail transit which has its civil and electrical structures at odds with its compeers. Moreover, excluding the LRT Kelana Jaya line, there are the London Underground and the Milan Metro Line 1 [9, 20], both of which are 
Table 2 Common Lightning Transient Incidents and Their Description

\begin{tabular}{ll}
\hline Incident & Description \\
\hline $\begin{array}{l}\text { Direct lightning strikes } \\
\text { Indirect lightning strikes }\end{array}$ & $\begin{array}{r}\text { A strike directly hits overhead wires, masts or tracks usually leading to system failure and disruption } \\
\text { A strike at a nearby building or ground creates a travelling overvoltage via cables and inductively induced } \\
\text { currents that damages or destroys unprotected electronic components }\end{array}$ \\
$\begin{array}{l}\text { Electromagnetic interference } \\
\text { fields }\end{array}$ & $\begin{array}{c}\text { A side issue of lightning strikes is known as electromagnetic interference affecting the interaction between any } \\
\text { different systems that are in close proximity due to lightning transients or overvoltage } \\
\begin{array}{l}\text { Occurrences within the } \\
\text { railway system }\end{array}\end{array}$ \\
\hline
\end{tabular}

underground metro transits which are a total contrast to the elevated LRT Kelana Jaya line. This places this study at a disadvantage as there are limited references available by only handful of researchers. In short, the aim of this study is tasked with establishing and seeking enlightenment concerning transient insulation coordination of power rails ensuring a proper relationship between fickle lightninginduced overvoltage faults with respective insulated rail brackets and surge arresters.

\section{Case Study and Electromagnetic Transients Program-Restructured Version (EMTP-RV) Modelling}

The LRT Kelana Jaya Line has a total length of $46.4 \mathrm{~km}$, 37 passenger stations and 24 traction power substations (TPSSs) [21]. Its $46.4 \mathrm{~km}$ route is a combination of $42.1 \mathrm{~km}$ of elevated tracks and $4.3 \mathrm{~km}$ of subway en route to Gombak from Putra Heights. This line has been in operation for the last 21 years, faithfully dedicating its services to 30,000 passengers per hour in each direction $[22,23]$. Throughout its two decades of service, the line has experienced technical disturbances and traction power loss due to lightning. The first incident was reported on 15 November 2010 when the line was struck by lightning during heavy rain on a Monday afternoon, which caused the train to fail to stop at its four out of five subway stations, namely KLCC, Kampung Baru, Dang Wangi and Masjid Jamek [24]. Three years later, on the late afternoon of 13 December 2013, a lightning strike unfortunately caused a loss of traction power in some areas, consequently causing delays and left the commuters stranded at the stations [25]. These incidents insinuated the call for a proper investigation, more so for an insulation coordination study.

Accordingly, for the sake of theoretical study of the effect of an indirect lightning strike on the insulation coordination a section of the $46.4 \mathrm{~km}$ route was secured, specifically the Setiawangsa Station to Damai Station as these elevated routes are in between an at-grade track (Sri Rampai Station) and a subway line (Ampang Park Station). The simulations were carried out using the EMTP-RV.

\subsection{Traction Power Substation}

The traction power substation is a facility of the electric power traction, functioning as a hub that steps down if not converting the incoming electric power from the national provider to the type and voltage level that are fit for the respective traction system. Aligned with this work, the incoming $33 \mathrm{kV}$ was stepped down to $585 \mathrm{~V}$ by a rectifier transformer before the AC voltage was rectified to a DC voltage as shown in Fig. 1.

\subsection{Power Rails}

As far as is known, a fourth rail transient study has not been done before, thus making reference to any past study harder as a basis for reference. Thereupon, a bold approach was taken in replicating the conceptualisation of tower surge impedance in order to portray the power rail surge impedance. The reason for this was simple. These two structures are more or less similar in terms of the conductor physical structure. Although the power rails share the same purpose as any transmission line, they do not share the same conductor structure. Unlike transmission lines whose cross sections are round and constructed from more than one conductor wire, power rails are a solid conductor with an irregular cross section [26] therefore, sharing more of a resemblance with the structure of a transmission tower.

The development of the model were applied through equations, (1), (2) and (3), appear to be more appropriate to apply to this study by making a comparison between the arrangement of the rails (Fig. 2a) to the most equivalent shape of transmission line tower (Fig. 2b) [27] which is the H-frame tower. 


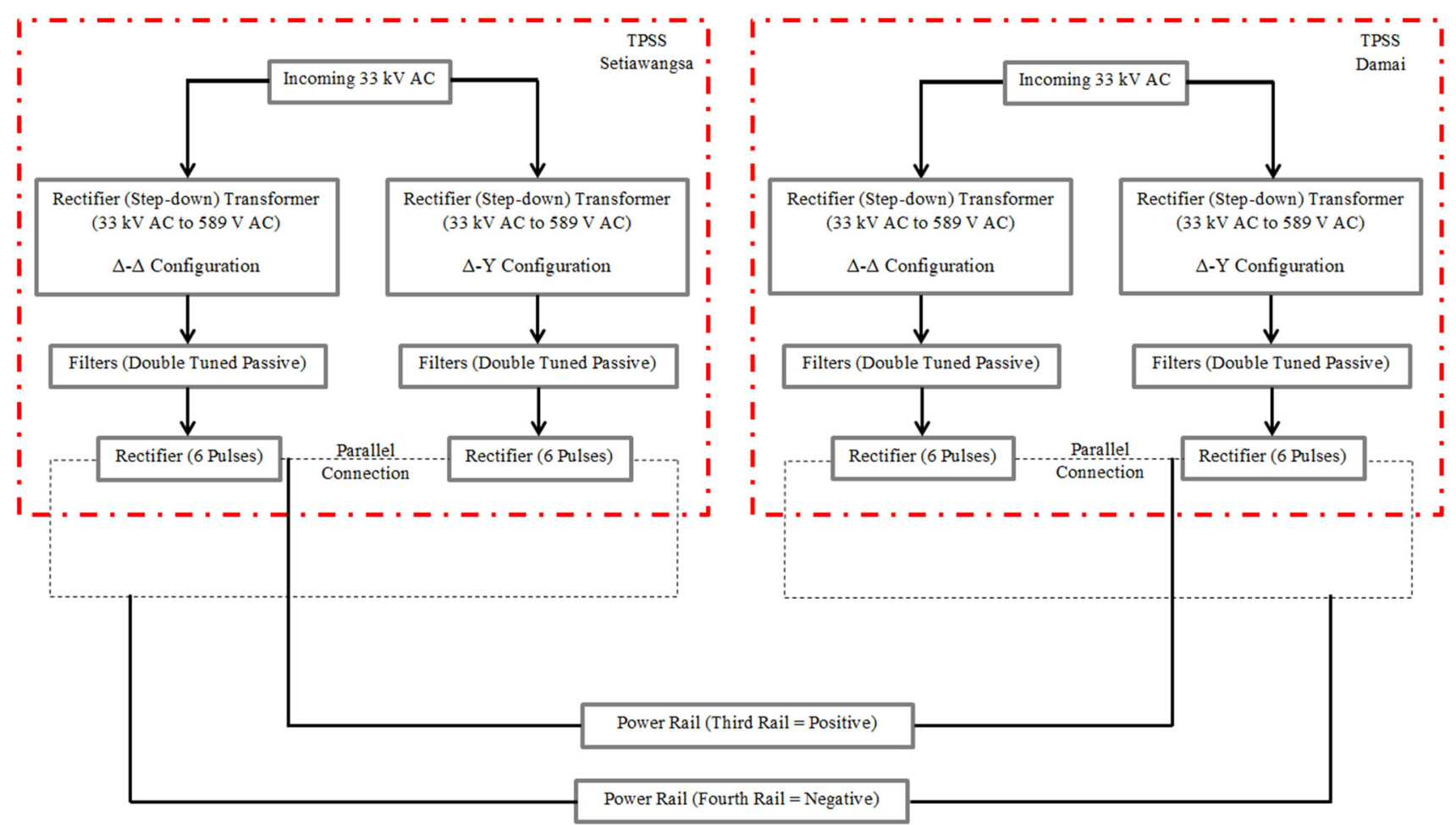

Fig. 1 Block diagram of the LRT Kelana Jaya system

Fig. 2 a The orientation of LRT Kelana Jaya power rails (b) the $\mathrm{H}$-frame tower model

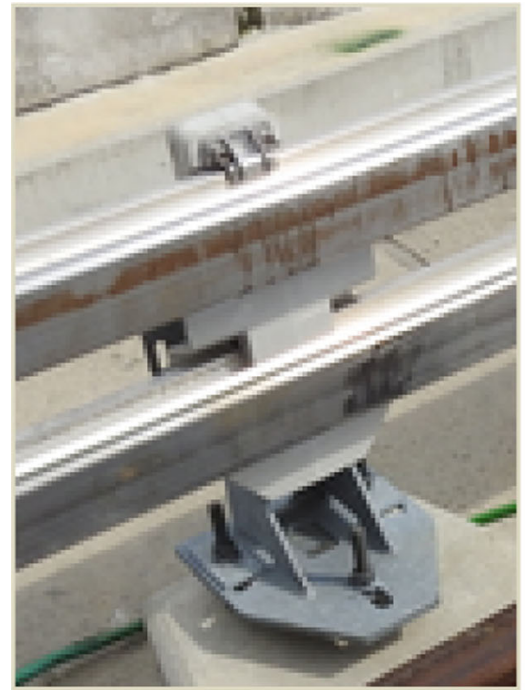

(a)

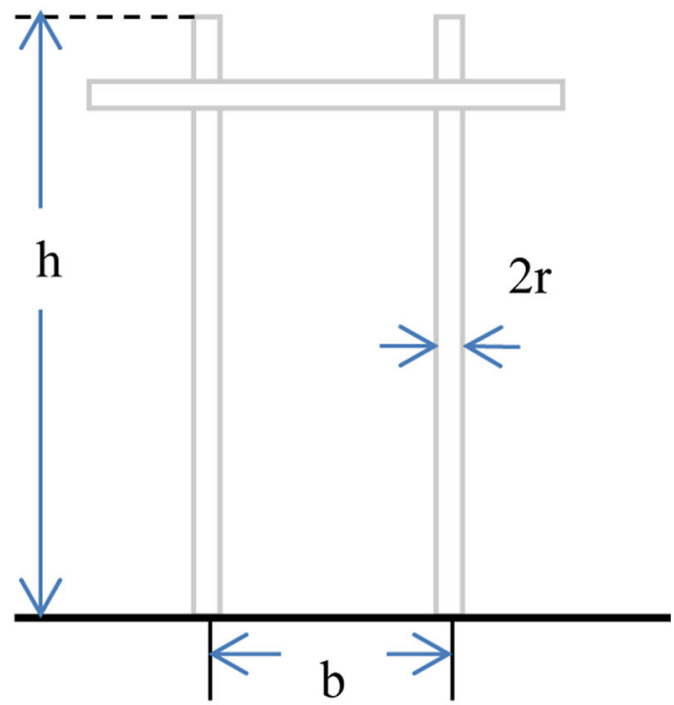

(b)
$\mathrm{Z}_{\mathrm{t}}=\frac{\mathrm{Zs}+\mathrm{Zm}}{2}[29]$

with

$Z_{\mathrm{s}}=60 \ln (L / r)+90(r / L)-60$

$Z_{\mathrm{m}}=60 \ln (L / b)+90(b / L)-60$

where $L$, the length of the power rail (m), $r$, the radius of the power rail $(\mathrm{m}), b$, the distance between the rails $(\mathrm{m}), \mathrm{Z}_{\mathrm{t}}$, the tower surge impedance $(\Omega), Z_{\mathrm{s}}$, self-impedance $(\Omega)$, $Z_{\mathrm{m}}$, the mutual impedance $(\Omega)$

\subsection{Insulated Rail Brackets}

The power rails of the LRT Kelana Jaya line are mounted parallel to each other, and as such, an insulator is essential 
in isolating the positive rail (third rail) from the negative rail (fourth rail). This insulator is known as the insulated rail bracket. The conceptualisation of the respective power rail insulated rail brackets is realised in the same manner as that in power line insulator study procedures, which embodies a capacitor, only that the dielectric as regards this study is cast epoxy (CE). Equation 4 is applied in quantifying the appropriate adaptation of capacitance to be used in this study.

$C=\frac{A \varepsilon_{0} \varepsilon_{r}}{d}$

where $C=$ capacitance, $A$ is the area between the plates $\left(\mathrm{m}^{2}\right), A=0.006764 \mathrm{~m}^{2}, d$ is the distance between the plates (m), $d=0.083 \mathrm{~m}, \varepsilon_{0}$ is the permittivity of the free space, $\varepsilon_{0}$ $=8.85 \times 10^{-12} \mathrm{~F} / \mathrm{m}, \varepsilon_{\mathrm{r}}$ is the permittivity of CE dielectric, $\varepsilon_{\mathrm{r}}$ $=4[28]$.

The presence of high-voltage stress on the power rails, where the structures are separated only by air and insulated rail brackets every $5 \mathrm{~m}$, is always expected to cause flashovers at the insulated rail brackets, unless surge arresters are installed along the power rails. This is because as the stress increases to a point that exceeds the electric strength of the air $\left(3 \times 10^{6} \mathrm{~V} / \mathrm{m}\right)[29,30]$ and the bracket material, a spark travels from one conductor rail to the other, and if the stress is sustained, this may also be followed by a continuous arc, hence a flashover. In modelling this fateful occurrence, a flashover switch was connected across the insulated rail brackets that closed accordingly when the presence of the high-voltage stress exceeded the calculated flashover voltage (FOV) of the bracket material. The bracket FOV was determined by Eq. 5 .

The flashover voltage of the insulated rail bracket was calculated through this calculation $[31,32]$ :

$V=\left(400+\frac{710}{t^{0.75}}\right) \times \ell$

where $V$ is the flashover voltage $(\mathrm{kV}), t$ is the time to flashover (range $0.5 \mu \mathrm{s}$ to $16 \mu \mathrm{s}$ ) and in this study it is $2 \mu \mathrm{s}$ [32], $\ell$ is the insulated rail brackets length $(\mathrm{m}), l=0.076 \mathrm{~m}$.

Note: According to IEEE STD 1410-2010, to obtain an estimated value for the critical flashover (CFO) for wet conditions, the dry CFO values were multiplied by $0.8 \pm 0.1$ [33]

On the other hand, BIL is the magnitude of voltage that yields $90 \%$ withstands and $10 \%$ failures, or in the words of the Standard IEEE 1410, "the crest value of a standard lightning impulse for which the insulation exhibits a 90 percent probability of withstands (or a 10 percent probability of failures) under specified conditions" [33] and expressed as in Eq. 6 [34, 35].

$$
B I L=C F O\left(1-1.28 \frac{\sigma_{\mathrm{f}}}{C F O}\right)
$$

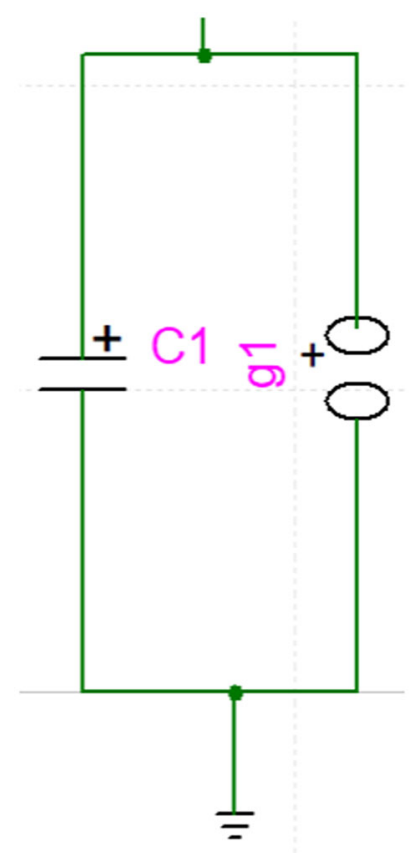

Fig. 3 The insulated rail brackets along with its flashover switch

with $\sigma_{\mathrm{f}}=$ coefficient of the variation, known as sigma. For lightning, the sigma is $2-3 \%$.

The insulated rail brackets along with its flashover switch are show in Fig. 3.

\subsection{Traction Substation Surge Arrester}

It is investigated that there is no surge arrester installed along the $3 \mathrm{~km}$ of the selected route as normally the arresters are installed in the vicinity of the electrical equipment they are protecting such as the station transformer or the station power rectifier. Thus, it is assumed that the installation locations of the arrester for this study are at the entrance of the DC side of the traction substation. Therefore, the arrester was modelled primarily through the IEEE model, as it offers advantages such as thorough consideration in designing the arrester through formulas that take into account both the electrical data (residual voltages) and the physical parameters (overall height, block diameter, number of columns) [14], and works splendidly with impulse current flow with a wave front between 0.5 and $45 \mu$ s [36, 37]. The respective designed IEEE model is shown in Fig. 4, with its parameters established through Eq. 7 to Eq. 11. The established parameters are tabulated in Table 3.

$L_{1}=\frac{15 d}{n}(\mu H)$ 
Fig. 4 The IEEE model [39]

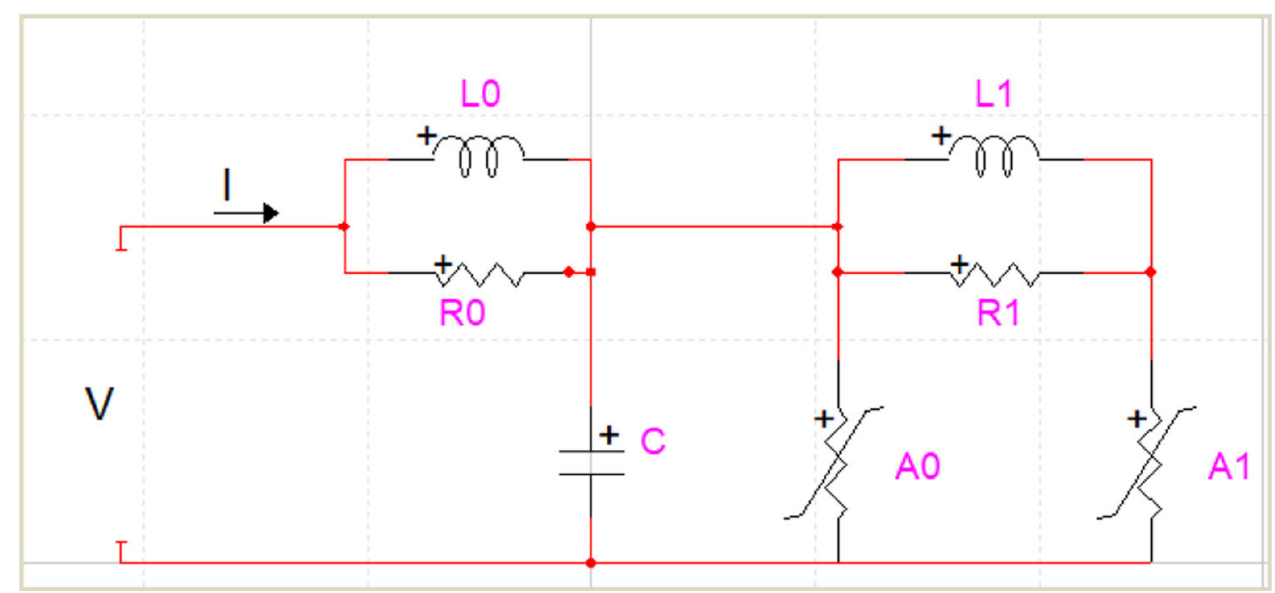

Table 3 Parameters of 3EB4-010 and PDTA09 Arresters

\begin{tabular}{llllll}
\hline Arrester model & \multicolumn{5}{l}{ Parameters } \\
\cline { 2 - 6 } & $\mathrm{L} 0(\mu \mathrm{H})$ & $\mathrm{L} 1(\mu \mathrm{H})$ & $\mathrm{R} 0(\Omega)$ & $\mathrm{R} 1(\Omega)$ & $\mathrm{C}(\mathrm{pF})$ \\
\hline 3EB4-010 & 0.039 & 0.03790 & 19.5 & 12.675 & 512.8205 \\
PDTA09 & 0.0322 & 0.02863 & 16.1 & 10.465 & 621.118 \\
\hline
\end{tabular}

$R_{1}=\frac{65 d}{n}(\Omega)$

$L_{0}=\frac{0.2 d}{n}(\mu H)$

$R_{0}=\frac{100 d}{n}(\Omega)$

$C=\frac{100 n}{d}(p F)$

where $d$ is the estimated height of the arrester (m), $n$ is the number of arrester columns in parallel [38].

\subsection{Indirect Lightning and LIOV Modelling}

The Kelana Jaya line is built and operated in the heart of Kuala Lumpur. Although the track bustles through the concrete jungle of Kuala Lumpur and may be shielded by the tall neighbouring buildings and is unlikely to be directly struck by lightning, still it is the effect of indirect lightning that is of interest to everyone concerned. This indirect lightning incident is then properly matched with the best fit of a lightning return stroke model for appropriate risk analysis of the insulation in the line.

The first step towards the evaluation and development of a return stroke model is to express the lightning current analytically. The lightning current of interest is the current at the channel base as to highlight the impact at the ground level without taking in the consideration of the spatial and temporal distribution of the current along the channel of the lightning propagation. Therefore, it is sufficient to express the current at the channel base through the Heidler function. For the evaluation of the current at different heights (in consideration of the spatial and temporal distribution of the current along the channel of the lightning propagation) the return stroke model can be expressed by selecting any model appropriately through the four classes of the return stroke models, namely the gas dynamic model, the electromagnetic models, the distributed circuit models and the engineering models [40]. Furthermore, the first derivative of the Heidler functions for $t=0$ is equal to zero [41-43]. This shows that the function does not have a discontinuity at the start. As according to Heidler [44], if field derivatives are investigated, the current function should be able to be differentiated at least twice without any discontinuity especially the first time derivation. Moreover, the Heidler function allows for reproduction of any lightning wave shape, through the modification of the wave shape steepness, its rise time, its fall time and its peak current [45]. And in order to reproduce a specific return stroke waveform, very often a combination of two Heidler functions is applied [46, 47]. This combination can be referred to Eq. 12.

$$
\begin{aligned}
I(0, t)= & \frac{I_{1}}{\eta_{1}} \times \frac{\left(\frac{t}{\tau_{11}}\right)^{n_{1}}}{1+\left(\frac{t}{\tau_{11}}\right)^{n_{1}}} \times \mathrm{e}^{\left(-\frac{t}{\tau_{12}}\right)}+\frac{I_{2}}{\eta_{2}} \times \frac{\left(\frac{t}{\tau_{21}}\right)^{n_{2}}}{1+\left(\frac{t}{\tau_{21}}\right)^{n_{2}}} \\
& \times \mathrm{e}^{\left(-\frac{t}{\tau_{22}}\right)}
\end{aligned}
$$

where

$$
\begin{aligned}
& \boldsymbol{\eta}_{1}=\exp \left[-\left(\frac{\tau_{11}}{\tau_{12}}\right)\right] \times\left(\frac{n_{1} \tau_{12}}{\tau_{11}}\right)^{\left(1 / \mathrm{n}_{1}\right)} \text { and } \\
& \boldsymbol{\eta}_{2}=\exp \left[-\left(\frac{\tau_{21}}{\tau_{22}}\right)\right] \times\left(\frac{n_{1} \tau_{22}}{\tau_{21}}\right)^{\left(1 / \mathrm{n}_{2}\right)}
\end{aligned}
$$


$I_{1}, I_{2}$, the channel base peak current value of the Heidler function, (kA).

$\tau_{1 \mathrm{n}}, \tau_{2 \mathrm{n}}$, the time constant of the wave front of the Heidler function, $(\mu \mathrm{s})$ for $\mathrm{I}_{1}$ and $\mathrm{I}_{2}$ respectively

$n_{1}, \mathrm{n}_{2}$, the exponent of the Heidler function (usually holds to a value between 2 and 10) [48].

$\eta_{1}, \eta_{2}$, the current amplitude correction factor of the Heidler function.

The resultant force from the lightning discharge at the ground level raises the ground potential, creating an induced effect between the guideway and the ground known as a lightning-induced voltage or overvoltage (LIOV) when the generated induced voltage exceeds its maximum steady state voltage. The evaluation of the LIOV was made possible through the closed-form solution of the Rusck model. A closed-formed solution is an analytical expression where the contributions along the lightning channel and type of lightning current are expressed using a finite number of standard mathematical operations. On the other hand, the Rusck model appeared to be analytically precise and rigorous $[19,49]$, although it appeared to be a simple expression. The Rusck model is expressed by Eq. 14.

$$
\begin{aligned}
v(x, t)= & \frac{\zeta_{0} I_{0} h}{4 \pi} \beta\left(\frac{c t-x}{d^{2}+\beta^{2}(c t-x)^{2}}\left(1+\frac{x+\beta^{2}(c t-x)}{\sqrt{(\beta c t)^{2}+\frac{x^{2}+d^{2}}{\gamma^{2}}}}\right)\right. \\
& \left.+\frac{c t+x}{d^{2}+\beta^{2}(c t+x)^{2}}\left(1+\frac{x+\beta^{2}(c t+x)}{\sqrt{(\beta c t)^{2}+\frac{x^{2}+d^{2}}{\gamma^{2}}}}\right)\right)
\end{aligned}
$$

where $\beta=\frac{v}{c}$ ( $\mathrm{v}$ is the return stroke velocity and $\mathrm{c}$ is the speed of light), $\zeta_{0}=376.730313 \Omega$ (free space characteristic impedance), $\mathrm{I}_{0}$ is the channel base current peak, $d$ is the horizontal distance and $x$ is the vertical distance from lightning stroke, $h$ is the guideway height, $\gamma=1 / \sqrt{1-\beta^{2}}$

\begin{tabular}{|c|c|c|c|c|c|}
\hline \multirow{2}{*}{$\frac{\text { Occurrence }}{\%}$} & \multicolumn{4}{|c|}{ Heidler Function setting } & \multirow{2}{*}{$\frac{\mathrm{I}_{0}(\mathrm{kA})}{\mathrm{I}_{0}}$} \\
\hline & $\mathrm{I}_{1}(\mathrm{kA})$ & $\tau_{11}(\mu s)$ & $\tau_{21}(\mu \mathrm{s})$ & $\mathrm{n}_{1}$ & \\
\hline & 46.49 & 5.86 & 143.997 & 2 & $90(9 / 200 \mu \mathrm{s})$ \\
\hline \multirow[t]{2}{*}{$5[50]$} & $\mathrm{I}_{2}(\mathrm{kA})$ & $\tau_{12}(\mu s)$ & $\tau_{22}(\mu \mathrm{s})$ & $\mathrm{n}_{2}$ & \\
\hline & 41.548 & 1.759 & 592.86 & 10 & \\
\hline
\end{tabular}

Table 4 Parameters of Heidler function for $\mathrm{I}_{0}$ Peak

\section{Results and Discussion}

Because of the unavailability of the lightning current parameters for the LRT Kelana Jaya line, the parameters considered in computing $\mathrm{I}_{0}$ followed the established values from the measurements of Berger et al. with probabilities of 5\% occurrence as shown in Table 4 . The resultant lightning current based on the parameters of Table 4 is shown by Fig. 5, i.e., $90 \mathrm{kA}(9 / 200 \mu \mathrm{s})$.

The phenomenon (shown by Fig. 6) that will be investigated herein is essentially an attempt to optimize the lightning insulation capabilities of the station lightning arrester. In what follows, this section shall limit the distance essentially to $50 \mathrm{~m}$ as to highlight the impact the induced effects have on different station lightning arresters, namely the 3EB4-010 arrester and PDTA09 arrester. Other parameters were set as shown in Table 5.

Figures 7 and 8 show the profile comparison between the lightning discharge current $90 \mathrm{kA}(9 / 200 \mu \mathrm{s})$ (amperetime profile) and the residual voltage of the 3EB4-010 arrester (volt-time profile) and the PDTA09 arrester (volttime profile) at the Setiawangsa Station and Damai Station, respectively. The performance profiles of the station arresters were superimposed for easier analysis. At a glance, it can be observed that the PDTA09 arrester displayed a much lower residual magnitude performance profile compared to the 3EB4-010 arrester.

For example, the initial peak residual voltage recorded by the PDTA09 arrester for both the Setiawangsa and Damai stations showed a value of $30 \%$ and $26 \%$, respectively, against the recorded initial peak residual voltages of the 3EB4-010 arrester at the same stations. On the flip side, the initial peak residual voltage recorded for both the arresters at the Setiawangsa Station was lower than the final residual magnitudes, whereas the arresters at the Damai Station recorded higher voltage. This is a response behaviour that seems to contradict the actual nature of a surge arrester. However, this may be comprehended after comparing and analysing the response behaviour of the Setiawangsa Station surge arresters against the impressed lightning current, with reference to Fig. 7 and its corresponding numerical data in Table 6 . As stated by the IEEE Working Group 3.4.11 1992, the residual voltage of the arresters correlate with its maximum magnitude point of time and the lightning peak current point of time. If the residual voltage reaches its maximum before the discharge lightning current reaches its maximum, the arrester is said to have a dynamic characteristic. Thus, by analysing Table 6, it can be seen that both the arresters started to clamp the incoming transient induced overvoltage approximately $18 \mu$ s earlier than the lightning discharge reached its maximum peak. Once the magnitude of the 
Fig. 5 Lightning current $90 \mathrm{kA}$ $(9 / 200 \mu \mathrm{s})$ wave shape

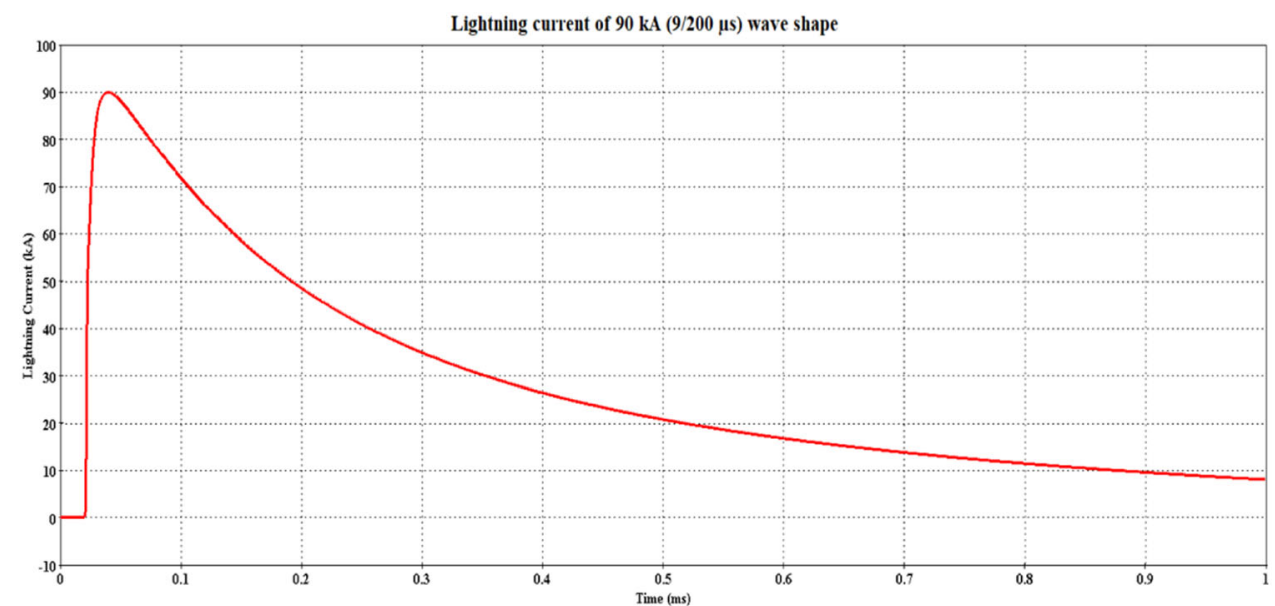

Fig. 6 Illustration of the simulation configuration

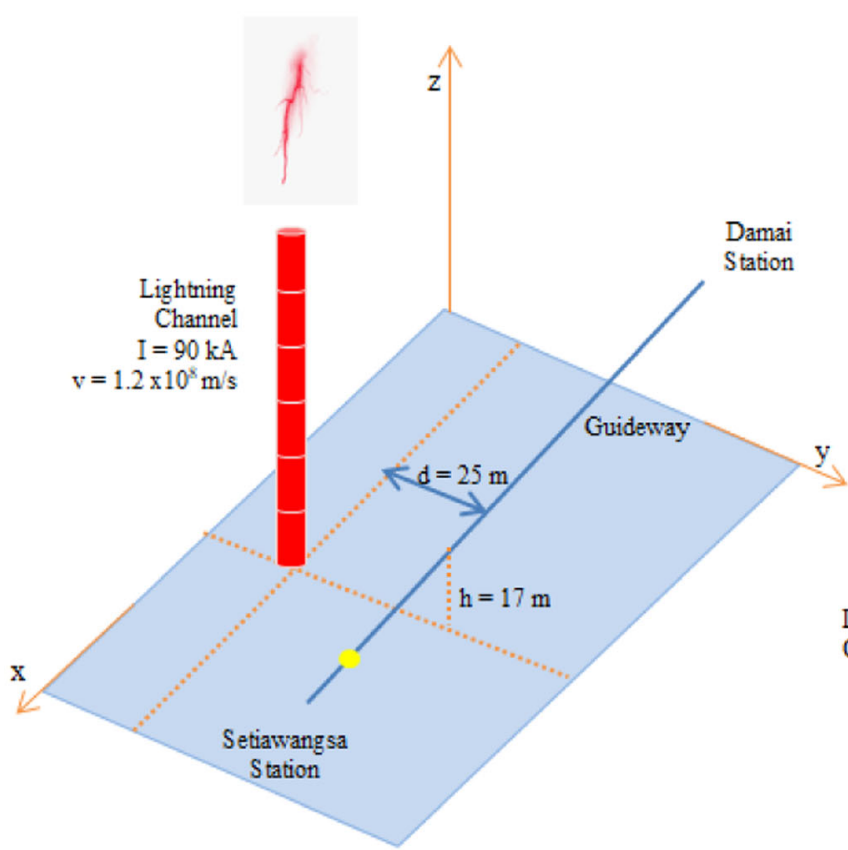

(a) axonometric view

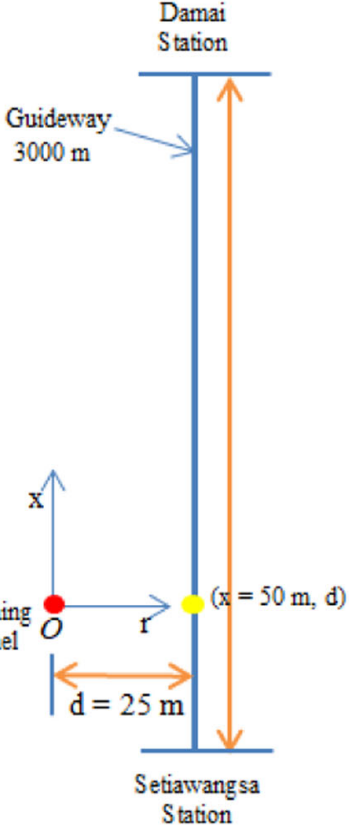

(b) top view

Table 5 Relative simulation variations

\begin{tabular}{|c|c|c|c|c|c|c|c|c|}
\hline \multirow{2}{*}{$\begin{array}{l}\text { Operating system } \\
\text { voltage }(\mathrm{V})\end{array}$} & \multirow{2}{*}{$\begin{array}{l}\text { System } \\
\text { length (m) }\end{array}$} & \multirow{2}{*}{$\begin{array}{l}\text { Height } \\
(\mathrm{m})\end{array}$} & \multirow{2}{*}{$\begin{array}{l}\text { Insulated rail } \\
\text { bracket }\end{array}$} & \multirow{2}{*}{$\begin{array}{l}\text { Arrester }(\text { residual } \\
\text { voltage }(\mathrm{kV}))\end{array}$} & \multirow{2}{*}{$\begin{array}{l}\mathrm{I} 0 \\
(\mathrm{kA})\end{array}$} & \multirow{2}{*}{$\begin{array}{l}\text { Velocity } \\
\text { (v) }\left(10^{8} \mathrm{~m} / \mathrm{s}\right)\end{array}$} & \multicolumn{2}{|l|}{ Strike point } \\
\hline & & & & & & & $\begin{array}{l}\text { Horizontal } \\
\text { (d) }(\mathrm{m})\end{array}$ & $\begin{array}{l}\text { Vertical } \\
\text { (x) (m) }\end{array}$ \\
\hline 750 & 3000 & 17 & $\mathrm{CE}$ & $\begin{array}{l}\text { 3EB4-010 (2.4) } \\
\text { PDTA09 (1.9) }\end{array}$ & 90 & 1.2 & 25 & 50 \\
\hline
\end{tabular}

lightning current was approximately more than half from its maximum discharge current, the arresters were quick to redirect the high voltage current to ground within $0.7 \mu \mathrm{s}$ (referring to the sharp fall of the tail wave shape), before flattening out at about $16 \mu \mathrm{s}$, thus proving their dynamic characteristics.

As for the Damai Station surge arresters, there was nothing peculiar about the residual voltage wave shape, 

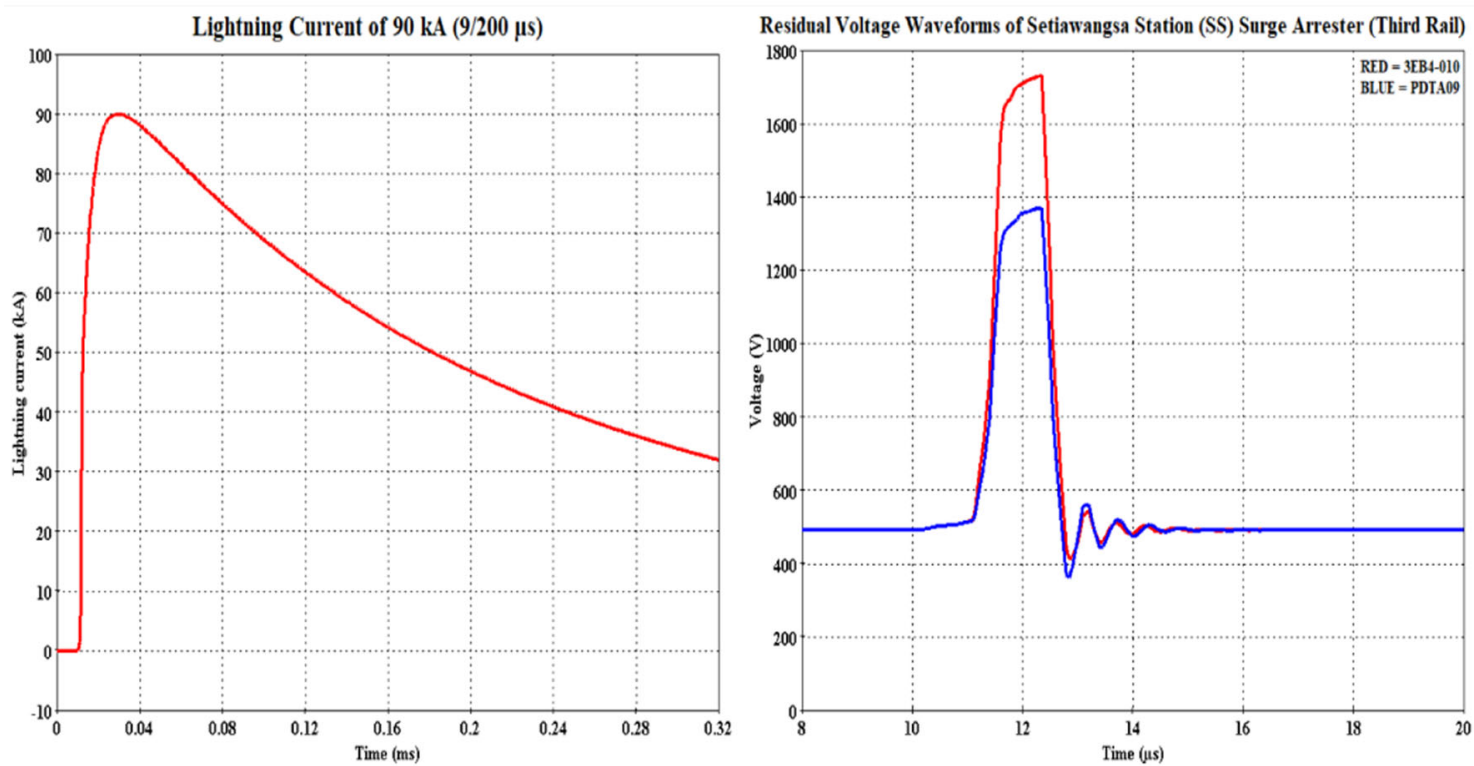

Fig. 7 The profile comparison between the lightning discharge current $90 \mathrm{kA}(9 / 200 \mu \mathrm{s})$ (ampere-time profile) and the residual voltage by the 3EB4-010 arrester (volt-time profile) and the PDTA09 arrester (volt-time profile) at the Setiawangsa Station

referring to Fig. 8. Likewise, the high voltage current was redirected to ground in an exponential decay manner, meaning that the high-voltage current decreased at a proportional rate of the lightning discharge current. A swift scan of the numerical data in Table 7 found that the PDTA09 arrester clamped the incoming induced overvoltage $0.1 \mu$ s later than the 3EB4-010 arrester, but still managed to redirect its $8 \%$ voltage current to the ground $0.05 \mu$ s earlier than the 3EB4-010 arrester.

Above all, it should be mentioned that all the simulations done in this work have a delay period of $10 \mu$ s so that the shape of the wavefront of any waveforms could be properly displayed for analysis. Hence, it should be remembered that all discussion concerning the point of occurrence is $10 \mu$ s earlier than the actual recorded period.

The $90 \mathrm{kA}(9 / 200 \mu \mathrm{s})$ waveform features not only a higher-magnitude discharge current, but also a longer wave-tail time. It is widely acknowledged that the severity of the damage caused by lightning-induced overvoltage brought onto any system is influenced by the lightning stroke magnitude and the wave-front duration. As a lightning stroke with shorter front time duration would impose a larger induced overvoltage on the system, a stroke with longer tail time duration tends to influence the thermal damage endured by the system components and also determines the amount of energy absorbed by the system surge arresters [51].

As such, by analysing the wave shape of the energy absorption in Fig. 9, the energy from the $200 \mu$ s wave-tail duration had a higher impact on the Setiawangsa Station (SS) arresters, as the lightning origin location was much
Table 6 The lightning discharge current and the arrester residual voltage data for Fig. 7

\begin{tabular}{|c|c|c|c|c|c|}
\hline & $\begin{array}{l}\text { Lightning } \\
\text { Discharge }\end{array}$ & \multicolumn{2}{|c|}{ 3EB4-010 arrester } & \multicolumn{2}{|c|}{ PDTA09 arrester } \\
\hline & \multicolumn{5}{|c|}{ Time $(\mu \mathrm{s})$} \\
\hline & 29.3 & 11.65 & 12.35 & 11.60 & 12.35 \\
\hline & Peak & Initial & Final & Initial & Final \\
\hline & ICan & Peak & Peak & Peak & Peak \\
\hline $\begin{array}{l}\text { Lightning } \\
\text { discharge } \\
(\mathrm{kA})\end{array}$ & 90.00 & 31.4099 & 50.3094 & 31.4099 & 50.3094 \\
\hline $\begin{array}{c}\text { 3EB4-010 } \\
\text { arrester }(\mathrm{V})\end{array}$ & - & 1635.59 & 1730.18 & 1565.81 & 1730.18 \\
\hline $\begin{array}{c}\text { PDTA09 } \\
\text { arrester (V) }\end{array}$ & - & 1298.80 & 1370.15 & 1261.51 & 1370.15 \\
\hline
\end{tabular}

closer to this station compared to the Damai Station (DS). The high energies absorbed by both arresters were quick to dissipate, referring to the sharp fall of the tail wave shape compared to the moderate time span of thermal dissipation by the Damai Station arresters. The high thermal energies were dissipated within $1 \mu$ s by both the arresters. Rest assured, the arresters may still work reliably and safely even though the energy absorption exceeded their standard allowable limit, given that the arresters have time to cool down. The necessary cool-down time for the arresters depends on their construction, the ambient temperature and the applied voltage. However, normally the cool-down time typically lies between 45 and 60 minutes [52]. Although the amount of the thermal energy absorbed by the SS PDTA09 was more than $200 \%$ of the limit permitted as analysed shown in Fig. 10, it was still much better than to have an amount absorbed that was more than $300 \%$ of the 

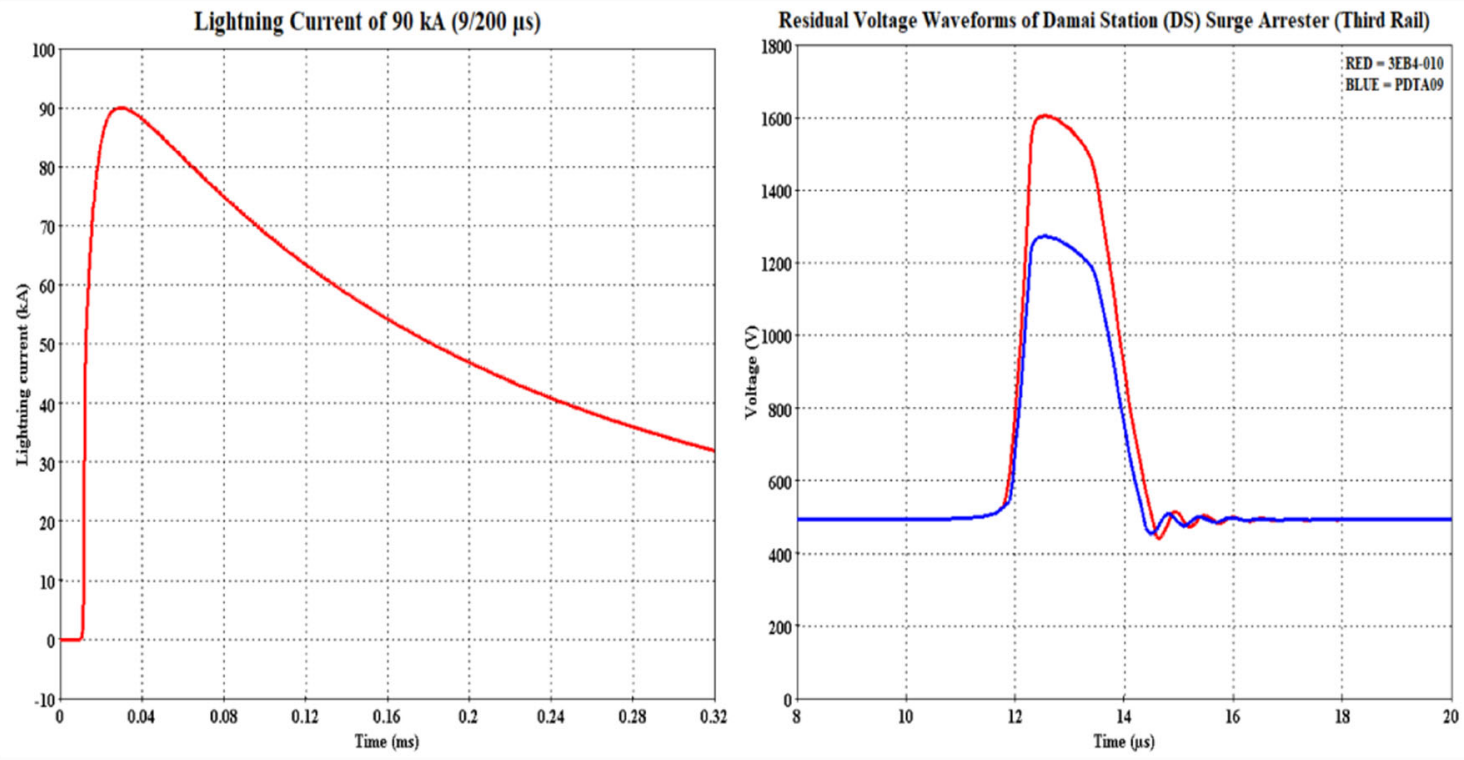

Fig. 8 The profile comparison between the lightning discharge current $90 \mathrm{kA}(9 / 200 \mu \mathrm{s})$ (ampere-time profile) and the residual voltage by the 3EB4-010 arrester (volt-time profile) and the PDTA09 arrester (volt-time profile) at the Damai Station

Table 7 The lightning discharge current and the arrester residual voltage data for Fig. 8

\begin{tabular}{cccccc}
\hline & $\begin{array}{c}\text { Lightning } \\
\text { Discharge }\end{array}$ & \multicolumn{2}{c}{ 3EB4-010 arrester } & \multicolumn{2}{c}{ PDTA09 arrester } \\
\hline & 29.3 & $\begin{array}{c}12.45 \\
\text { Initial }\end{array}$ & $\begin{array}{c}13.40 \\
\text { Final }\end{array}$ & $\begin{array}{c}12.55 \\
\text { Initial } \\
\text { Peak }\end{array}$ & $\begin{array}{c}13.45 \\
\text { Final } \\
\text { Peak }\end{array}$ \\
& Peak & Peak & Peak & Peas & \\
$\begin{array}{c}\text { Lightning } \\
\text { discharge } \\
(k A)\end{array}$ & 90.00 & 50.3094 & 56.0693 & 50.3094 & 56.0693 \\
$\begin{array}{c}\text { 3EB4-010 } \\
\text { arrester }(V)\end{array}$ & - & 1601.62 & 1485.31 & 1605.14 & 1454.62 \\
$\begin{array}{c}\text { PDTA09 } \\
\text { arrester }(V)\end{array}$ & - & 1270.54 & 1190.41 & 1273.05 & 1172.60 \\
\hline
\end{tabular}

limit permitted $(10 \mathrm{~kJ})$ in the long run as in the case of the absorptivity of the SS 3EB4-010. If the absorbed energy exceeds the thermal energy absorption limit, it will put the arrester into a thermal runway condition $[53,54]$. Thermal runway is a condition where an increase in temperature changes the arrester electrical characteristics in a way that it eventually becomes conductive even under the normal maximum continuous operating voltage.

Furthermore, a lightning current with higher magnitude tends to degrade the arrester much faster than a lower magnitude of lightning current. For example, a double strike of $65 \mathrm{kA}(8 / 20 \mu \mathrm{s})$ caused the leakage current to increase by 50\% [27]. Moreover, the accumulation of allowable surges causes the resistance of the arresters to decrease when the magnitude of the lightning current increases. For instance, 50 years of arrester life service would be able to be maintained if throughout its service years it was hit by an accumulation of 130 surges of $50 \mathrm{kA}$ or 30 surges of $100 \mathrm{kA}$ [27]. It is necessary to bear in mind that the likelihood of such surges with a severe wave-tail and magnitude is less common. For instance, the lightning current of $90 \mathrm{kA}(9 / 200 \mu \mathrm{s})$ employed in this study only represents $5 \%$ of the lightning occurrences throughout the 8 years of lightning current measurements conducted by Berger et al. in Switzerland [55]. To give a more impactful analogy, that would be $5 \%$ throughout the 2928 days or 70,080 hours over the 8 years of lightning current measurements. Thus, it would be wise to opt for an economical arrester that serves better when subjected to the same thermal energy absorption limit. In consideration of the advantages possessed by the PDTA09 as previously discussed in the first scenario case, this just goes to prove the better characteristics of the PDTA09.

\section{Conclusion}

The purpose of this study is to share an insight of the results for the simulation that had been done in investigating the insulation coordination performances between the insulated rail brackets and the station surge arresters if they were induced by a negative first return stroke. The coordination performances between the brackets and the arresters were studied under the $90 \mathrm{kA}(9 / 200 \mu \mathrm{s})$ lightning current. The lightning current was modelled by the sum of two Heidler functions representing the current at the channel base and the lightning-induced overvoltage was modelled by the Rusck Model. 
Fig. 9 The energy absorption waveforms of the Setiawangsa Station and Damai Station surge arresters
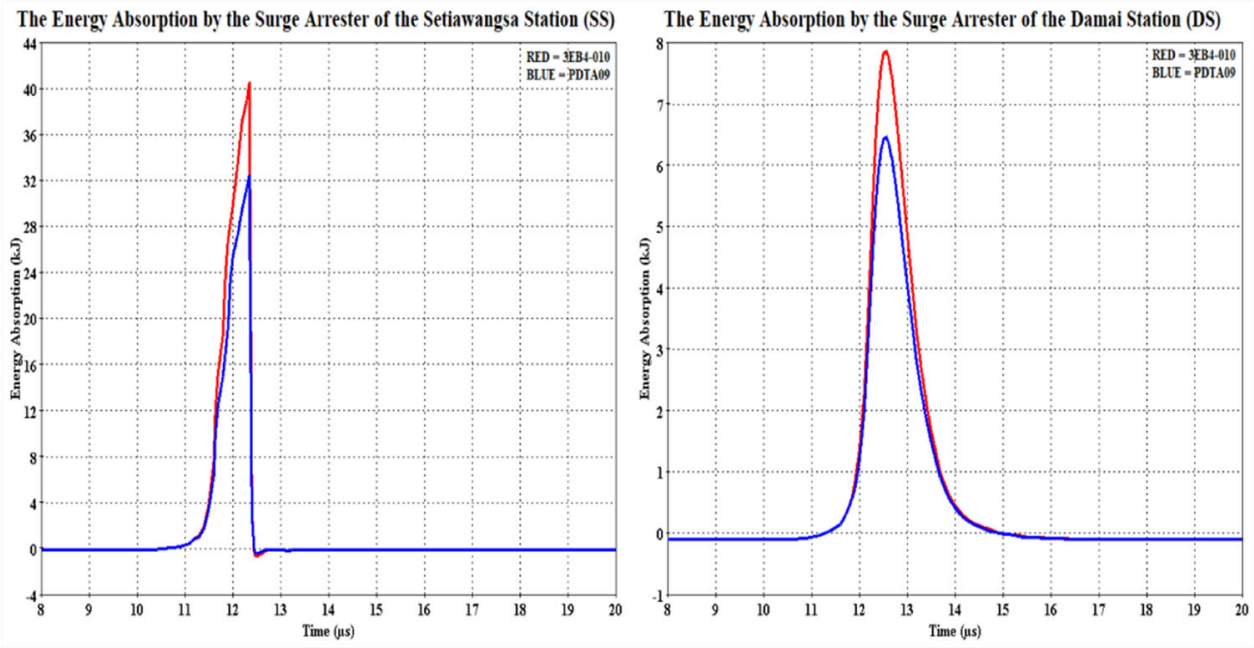

Thermal Energy Absorption Comparison

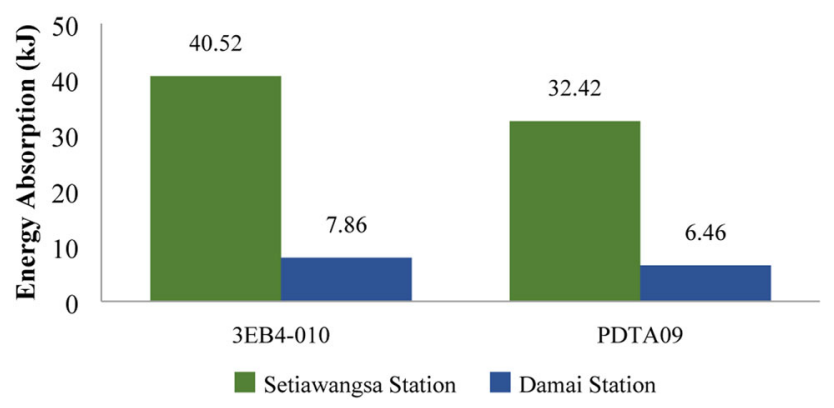

Fig. 10 Comparison of the thermal energy absorption magnitudes between the 3EB4-010 arrester and the PDTA09 arrester

The analyses led to a conclusion that the escalation of the lightning-induced overvoltage on the station arresters is heavily influenced by the arresters electrical characteristics. An arrester with a lower residual voltage limit such as the PDTA09 displayed a much lower residual magnitude performance profile and has a more dynamic response. An arrester with a low residual voltage characteristic such as the PDTA09 arrester is known for its better non-linearity, hence capable of clamping the lightning current to a lower residual voltage. Moreover, clamping at a lower residual voltage eventually results in better voltage gradient in the pre-breakdown region and a decrease in residual voltage ratio in the high current region.

In short, these simulation tests were done ensuring a reliable operation of the fourth rail transit. Thus, it is necessary to investigate lightning transient incidents on the system, so that an effective protection against lightning can be explored to realise design possibilities. As this study was conducted under the $90 \mathrm{kA}(9 / 200 \mu \mathrm{s})$ lightning current, for a similar study under different lightning current the results would likely be different. This would be the subject for future works.
Throughout the progress of this study, a few variables were ignored in order to produce a simpler simulation model and to not be a hindrance to the computational speed. For example, the effect of power rail curvature, the transit running rails and the transit cars were ignored during the stage of modelling the fourth rail DC light rail transit system, despite the fact that it is unlikely that the system was absent from these features. Simulation of such features in future work could possibly lead to increasing the accuracy of the predicted results.

Acknowledgements The authors thank the Strategic Hired Research Team Institute of Power Engineering (IPE) for their support either academically or professionally on this work.

Open Access This article is licensed under a Creative Commons Attribution 4.0 International License, which permits use, sharing, adaptation, distribution and reproduction in any medium or format, as long as you give appropriate credit to the original author(s) and the source, provide a link to the Creative Commons licence, and indicate if changes were made. The images or other third party material in this article are included in the article's Creative Commons licence, unless indicated otherwise in a credit line to the material. If material is not included in the article's Creative Commons licence and your intended use is not permitted by statutory regulation or exceeds the permitted use, you will need to obtain permission directly from the copyright holder. To view a copy of this licence, visit http://creativecommons. org/licenses/by/4.0/.

\section{References}

1. Siemens Industry Inc (2014) Insulation Coordination StudiesSelection of Insulation Strength for System Equipment. Erlangen, Germany

2. Woodworth J "Insulation Coordination FAQ," Arrester Works, 2010. [Online]. Available: http://www.arresterworks.com/ser vices/insulation_studies.php. [Accessed: 17-Nov-2019].

3. Shahan Z "History of Wind Turbines," Renewable Energy World, 2014. [Online]. Available: https://www.renewableenergy world.com/2014/11/21/history-of-wind-turbines/\#gref. [Accessed: 23-Nov-2019]. 
4. Energy Matters Webmaster "Solar Panel Brief History and Overview," Energy Matters, 2018. [Online]. Available: https:// www.energymatters.com.au/panels-modules/. [Accessed: 23-Nov-2019].

5. UITP (2018) "World Metro Figures 2018," Brussels, Belgium.

6. Li B, Qi R, Du Y, and Chen M (2018) "Lightning surge analysis in light rail transit using the FDTD method." 34th Int Conf Light Prot ICLP 2018(152100): 1-6

7. Charalambous CA, Cotton I, Aylott P (2008) A simulation tool to predict the impact of soil topologies on coupling between a light rail system and buried third-party infrastructure. IEEE Trans Veh Technol 57(3):1404-1416

8. Fichera F, Mariscotti A, and Ogunsola A (2013) "Evaluating stray current from DC electrified transit systems with lumped parameter and multi-layer soil models." In IEEE EuroCon 2013: 1187-1192.

9. Rahman FAA, Kadir MZAA, Osman M, Amirulddin UAU (2020) Review of the AC overhead wires, the DC third rail and the DC fourth rail transit lines: Issues and challenges. IEEE Access 8:1-1

10. Team Railway Technology, "DEHN Protects the Railway Infrastructure," DEHN SE + Co KG. [Online]. Available: https:// www.dehn-international.com/en/dehn-protects-railway-technol ogy. [Accessed: 03-Sep-2019].

11. Morita G et al. (2016) "Experimental study on new type earth mesh in railway substations aimed at lightning protection." In 2016 33rd International Conference on Lightning Protection, ICLP 1-6.

12. Hayashiya $\mathrm{H}$, Koguchi N, Yamamoto H, Ozaki T, Sakurai $\mathrm{T}$ and Inoue R (2012) "Improvement of grounding system of DC traction substation in railway power supply system: Advansed attempts of East Japan Railway Company.” 31st Int Conf Light Prot ICLP, 1-6

13. Wanjari PAV (2014) Effect of Lightning on the Electrified Transmission Railway System. Int J Adv Res Electr Electron Instrum Eng 3(7):10663-10671

14. Rousseau A, Rougier G, Aragones A (2018) "Improved tramway surge protection.” 34th Int Conf Light Prot ICLP 2018:1-7

15. Zhou Q and Du Y (2006) "Analysis of Lightning Transients in a DC traction power system of electrified railway using EMTP."4: 1831-1835

16. Polimac V, Jhutty A and Fraser M (1999) "Application of HV Insulation Coordination Techniques to DC Railway Systems." In High Voltage Engineering Symposium, 2.372-2.376.

17. Zoro R, Pakki RR, and Komar R (2017) "Lightning protection for electric railway in Indonesia telecommunication and signalling system." Int Conf High Volt Eng Power Syst ICHVEPS 2017-Janua: 476-478

18. Hayashiya $\mathrm{H}$ et al (2010) "Proposal of lightning risk assessment method based on the lightning current probability function for railway power supply system." 30th Int Conf Light Prot ICLP 2010:1-6

19. Hanekom A "Session Eleven: Lightning Protection of Rail and Related Industries The rail environment." In Earthing, Lightning \& Surge Protection Conference-IDC Technologies, 1-5.

20. Frey S (2012) Railway Electrification Systems \& Engineering, First. White Word Publications, Delhi, India

21. Konsortium CMC-COLAS-Uniway, "Kelana jaya line extension project: Power supply overall traction system description," 2019.

22. Railway Technology Webmaster, "Railway Technology Kuala Lumpur," 2019. [Online]. Available: https://www.railway-tech nology.com/projects/kuala-lumpur-driverless-metro/. [Accessed: 24-Oct-2019].

23. Masirin MIM, Salin AM, Zainorabidin A, Martin D, Samsuddin N (2017) Review on Malaysian Rail Transit Operation and Management System: Issues and Solution in Integration. IOP Conf Series: Mater Sci Eng 226(1):1-8
24. Citizen Journalist Malaysia (2010) “Putra LRT subway service delayed after lightning," Citizen Journalist Malaysia

25. Joibi N "LRT service breaks down during peak hour." The Star, 11-Feb-2013.

26. Wang Y-J, Wang J-H (2000) Modeling of Frequency-Dependent Impedance of the Third Rail Used in Traction Power Systems. IEEE Trans Power Deliv 15(2):750-755

27. Grebovic S (2016) Energy Stresses of Transmission Line Surge Arresters Due to Lightning Discharges. Graz University of Technology, Graz

28. Synthane Taylor, "Cast Epoxy Insulators," Synthane Taylor, 2018. [Online]. Available: http://www.synthanetaylor.com/castepoxy-insulators/. [Accessed: 29-Jul-2020].

29. Delfino F, Procopio R, Rossi M (2006) A field-to-line coupling model for overvoltage analysis in light-rail transit DC traction power systems. IEEE Trans Power Deliv 21(1):270-277

30. Cooray V (2015) An Introduction to Lightning, 1st edn. Springers, Uppsala, Sweden

31. IEEE Power Engineering Society (1997) IEEE Std 1243-1997: IEEE Guide for Improving the Lightning Performance of Transmission Lines

32. Whitehead JT et al. (1993) "IEEE Working Group Report Estimating Lightning Performance of Transmission Lines II-Updates to Analytical Models."

33. The Lightning Performance of Overhead Lines Working Group for IEEE and 1410 (2011) IEEE STD 1410-2010: Guide for Improving the Lightning Performance of Electric Power Overhead Distribution Lines 2010

34. Zawani N, Faizuhar M (2013) Modelling of $132 \mathrm{kV}$ overhead transmission lines by using ATP/EMTP for shielding failure pattern recognition. Procedia Eng 53:278-287

35. Hileman AR (2001) Insulation Coordination for Power Systems $17(2)$

36. Abu Bakar H (2015) "Fast Transient Simulation of IEEE Recommended Surge Arrester Model on a Transmission Line Using Alternative Transient Program (ATP)," Universiti Tun Hussien Onn, Malaysia

37. Muhamad Y (2015) "Fast Transient Simulation of Pinceti Surge Arrester Model on a Transmission Line Using ATP Software," Universiti Tun Hussein Onn Malaysia

38. Acer Voltage Ltd., "Surge Arresters Overvoltage Limiters," Hradec Kralove, Czech Reoublic.

39. Hsiao S (2012) "Simulation and Analysis of Metal-Oxide Surge Block Arrester Dynamic Characteristics," J Chinese Inst Eng 2013, 1-11

40. Djalel D, Ali H, Fayçal C (2007) The return-stroke of lightning current, source of electromagnetic fields (study, analysis and modelling). Am J Appl Sci 4(1):42-48

41. Vujević S, Lovrić D (2010) Exponential approximation of the heidler function For the reproduction of lightning current wave shapes. Electr Power Syst Res 80(10):1293-1298

42. Lovrić D, Vujević S, Modrić T (2013) On the estimation of heidler function parameters for reproduction of various standardized and recorded lightning current wave shapes. Int Trans Electr Energy Syst 23(2):290-300

43. Diendorfer G, Uman MA (1990) An improved return stroke model with specified channel-base current. J Geophys Res 95(D9):13621-13644

44. Heidler F, Cvetić J (2002) A class of analytical functions to study the lightning effects associated with the current front. Eur Trans Electr Power 12(2):141-150

45. Terespolsky BR (2015) An Approximation to the Heidler Function with an Analytical Integral for Engineering Applications Using Lightning Currents. University of Witwatersrand, Johannesburg 
46. Wooi CL, Abul-Malek Z, Hafizi Rohani MNK, Bin Yusof AM, Arshad SNM, Elga ar AI (2019) Comparison of lightning return stroke channel-base current models with measured lightning current. Bull Electr Eng Informatics 8(4):1478-1488

47. Mottola F (2007) "Methods and Techniques for the Evaluation of Lightning Induced Overvoltages on Power Lines. Application To Mv Distribution Systems for Improving the Quality of Power Supply." 158

48. Praneeth KN, Chandrasekaran K, Kumar S, and Punekar GS, "Estimation of Steep Fronted and Full Wave Lightning ChannelBase-Current Function Parameters using Genetic Algorithm." $1-7$.

49. Izadi M, Ab Kadir MZA, Hajikhani M (2014) On the lightning induced voltage along overhead power distribution line. J Electr Eng Technol 9(5):1694-1703

50. Ramarao G, Chandrasekaran K (2019) evaluating lightning channel-base-current function parameters for identifying interdependence of wavefront and tail by PSO method. IEEE Trans Electromagn Compat 61(1):183-190

51. Malcolm N, Aggarwal RK (2015) The impact of multiple lightning strokes on the energy absorbed by MOV surge arresters in wind farms during direct lightning strikes. Renew Energy 83:1305-1314
52. ABB Switzerland Ltd (2018) Overvoltage Protection Metal-Oxide Surge Arresters in Medium-Voltage Systems (Application Guidelines), 6th edn. ABB Switzerland Ltd, Wettingen, Switzerland

53. Pourakbari-Kasmaei M, Lehtonen M (2020) Enhancing the protective performance of surge arresters against indirect lightning strikes via an inductor-based filter. Energies 13(4754):1-31

54. Hamza A-SHA (1997) Application of surge arresters for the protection of Sf6 substations. Energy Convers Manag. 38(2):131-149

55. WG C4.407 (2013) Lightning Parameters for Engineering Applications. Cigre, 2013

56. Hirahara K (2012) Malaysia kelana jaya line power supply system. Meiden Rev 156(3):1-4

57. Izadi M, Ab Kadir MZA and Hajikhani M (2015) On the lightning electromagnetic fields due to channel with variable return stroke velocity. Math Probl Eng, vol. 2015, no. April 2016, 2015

58. Rameli N, Ab Kadir MZA, Izadi M, Gomes C, Jasni J (2013) Evaluation of lightning induced voltage due to the effect of design parameters on medium voltage distribution line. J Teknol Sci Eng 64(4):151-155 